\title{
Is Neighborhood Green Space Associated with A Lower Risk of Type 2 Diabetes in elderly? Evidence From Shanghai, China
}

\author{
Ye Zhan, Tongji University, China \\ Ying Zhu, Tongji University, China \\ Yifan Yu, Tongji University, China \\ Yining Liu, Shanghai Surveying and Mapping Institute, China
}

\begin{abstract}
Background: The elderly is the main group of patients with type 2 diabetes mellitus (T2DM). The incidence rate of T2DM is closely related to physical activity and environment. There are many literatures that have proved that green space has important influence on the health level of patients with T2DM. However, due to spatial non-stationarity, it is difficult for traditional linear regression models to explain the geographic spatial variation of prevalence and related driving factors. Besides, most of the studies focus on large-scale urban green space, and ignore the green space inside residential area which are also closely related to the daily life of the elderly.

Purpose: (1) To investigate association between T2DM and neighborhood green space supply. (2) To investigate association between T2DM and walking accessibility to green space within the residential environment. (3) To assess the current status of community green space supply in Yangpu District for finding problems and proposing corresponding measures to build a healthier community.
\end{abstract}

Method: The research subjects were 318,686 people aged 60 years and older living in 306 neighborhood committees (administrative divisions in China), Yangpu District, Shanghai, China. Among them 32,609 were diagnosed with T2DM. The prevalence data comes from the district government statistics, and the green space data extracted by the Shanghai Surveying and Mapping Institute are reliable. Through the API of AMAP, the walking path planning function was called to capture the shortest walk time from the neighborhood to the park, as well as the number of parks within 15 minutes of the neighborhood. Then calculate the comprehensive green space accessibility index through factor analysis. Finally, GWR (Geographically weighted regression) were performed in ArcGIS to fit associations between medically diagnosed T2DM and green space supply in order to explore the spatial variation of the prevalence and related driving factors .

Findings: The average T2DM in the elderly in the study area is 10\%, GWR results showed that there was a certain spatial heterogeneity in the prevalence. The ratio of neighborhood committee green space $\left(-0.19<C_{0}<-0.41\right)$, the ratio of green space in residential area $(-0.04<C 0<-0.24)$, the comprehensive green space accessibility index $(-0.03<\mathrm{Co}<-0.11)$ were had a certain negative impact on T2DM. It also showed that the coverage ratio of neighborhood committee green space had a greater impact on the dependent variables among the three green space supply indicators. The green space in residential area was also correlated with the T2DM, which reflected the characteristics of green space being cherished as a limited resource in the highdensity residential environment in Shanghai. In this environment, the accessibility of green space also had a certain importance. The bivariate local Moran's I statistic results revealed that the "high-low" clusters appeared in some communities in the northern and central regions, which means that although these communities had a higher coverage ratio of green space, the green 
space accessibility was low. This may cause obstacles to the use of the elderly.

Conclusions: This study innovatively uses geographically weighted regression, which embeds the spatial position of the data into the regression equation, to detect the spatial change of T2DM and its driving factors. And we speculate that green space has a mediating effect on the health level of the elderly. Finally, for the central urban area of a city with a high-density built environment like Shanghai, increasing large-scale green space is a huge challenge. What is feasible is that we can improve the supply of urban green space and the mediating effect by increasing the small green spaces in and around residential areas and improving the accessibility of green spaces.

\section{Keywords}

Green Space, elderly, T2DM, Geographically Weighted Regression, Shanghai

\section{INTRODUCTION}

\subsection{Background}

According to the results of China's seventh population census (2020), the population aged 60 and over accounted for $18.70 \%$ (of which the population aged 65 and over accounted for $13.50 \%$ ). Compared with the data of the sixth population census (2010), the proportion of the population aged 60 and over increased by 5.44 percentage points. This shows that China's aging degree has a further deepening trend, and the problems related to aging will become more prominent in the future, and problems related to the health of the elderly will inevitably become the focus.

In 2015, the World Health Organization (WHO) released the "World Report On Aging And Health", which emphasized that society should create a safe, independent and comfortable community environment for the elderly on the basis of Healthy Aging. The research contents of healthy aging mainly include aging and life course, age friendly environments, health systems that meet the needs of old people and long-term care system $(\mathrm{WHO}, 20)$. It can be seen that health and happiness depend not only on genes and individual characteristics, but also on the material and social environment in which we live ().

Many international studies have revealed that the urban built environment may have a direct or indirect impact on the physical activities, social communication and mental health of the elderly through transportation, park green space, medical facilities and activity facilities, so as to affect the physical health level of the elderly and bring different health outcomes. (Higgs P,2003; WHO, 2007; Kent J, 2014; Steels $\mathrm{S}, 2015)$.

The physical health level and activity ability of the elderly tend to decrease with the increase of age. Among many chronic diseases closely related to the elderly, type 2 diabetes significant is closely related to physical activity and environment. Effective environmental intervention has a more significant impact on the health of patients with T2DM (Lee C, 2013). According to the global diabetes report (2015), diabetes mellitus is the eighth risk factor leading to death. About 1.5 million people die of diabetes every year, and its epidemic rate is expected to increase in the next decade ("Intemnational Diabetes Federation", 2015). Meanwhile, the elderly group is a high incidence of diabetes. Since the blood glucose level of normal people increases with age, the increase of plasma glucose is observed after the age of 50 . The incidence rate of diabetes in middle and old aged people increases with age. About 415 million of the adult diabetic patients in the world are around the world, and about $3 / 4$ of the patients are below 65 years old (Cho N, 2018). Therefore, effective interventions for type T2DM are of greater significance for elderly diabetic patients. 


\subsection{Green Space Exposure Association with T2DM}

In an urban environment, green space can be defined as open space with natural elements, such as parks, playgrounds, and recreation areas, which can be used by the public for personal or social activities (Labib S. 2020). As an important part of built environment, the exposure of green space is combined with other environmental risk factors as predictors of diabetes (De la Fuente F, 2020).

Many studies have found that there is a close correlation between the exposure of green space and the prevalence of T2DM, physical activity and obesity (De la Fuente F, 2020; Ngom R, 2016; Sidawi B, 2014; Clark C, 2017; Bodicoat D.H, 2014). It is difficult to directly measure the actual exposure of green space, so the potential exposure of green space was usually measured to evaluate the availability of green space and the opportunity access to green space (Labib S, 2020). The common green space exposure measurement indicators in the existing research can be divided into availability, accessibility and visibility (Labib S, 2020). Green space availability refers to the scale characteristics of green space, such as the number and size of green space in the research unit, Normalized Difference Vegetation Index (NDVI), etc. In an Australian community study, Geographic Information System was used to identify the green space availability within a 1-km buffer from a participant's place of residence, and its correlation with the prevalence of T2DM was emphasized. It was found that people in high green space exposure environment had a lower risk of T2DM (Astell-Burt T, 2013). Green space accessibility refers to the possibility of people access to green space, usually refers to the spatial proximity, such as the time and distance to reach the green space. Through literature review, it was found that neighborhood green spaces have a significant correlation with reducing the prevalence of T2DM. It is concluded that improving neighborhood walkability and access to green space and other built environment characteristics can effectively prevent type 2 diabetes to some extent but current evidence is limited in terms of quantity and quality of research. (Den Braver N R, 2018; Dendup T, 2018). Green space visibility refers to the level of green space perceived by people during travel. Street view images are usually used to identify or measure the green visibility subjectively. In general, there are few studies based on this type of indicator (Labib S, 2020).

\section{METHODOLOY}

Based on the availability and accessibility of green space, this paper characterized the exposure level of green space, and analyzed the relationship between green space and the prevalence rate of type 2 diabetes among the elderly over 60 years old in Yangpu District of Shanghai. In general, There were three objectives in this study:

(1) To explore the relationship between the supply of green space and T2DM in neighborhood scale. (2) To explore the relationship between the accessibility of green space and T2DM. (3) Through the evaluation of the current situation of community green space supply in Yangpu District, to find out the existing problems and put forward the corresponding urban countermeasures, in order to build a healthier community.

\subsection{Morbidity data}

A total of 32,609 health records were collected from patients over 60 years old and diagnosed with type 2 diabetes in Yangpu District, Shanghai (data from Shanghai health department). Taking census-plot, which refers to China's sixth population census unit and a class of administrative divisions, as the basic spatial unit of study. The population data over 60 years old in the census-plot were from China's sixth population census report and the statistical yearbook of Yangpu District. It should be noted that due to the problem of time lag in population data, the average growth rate of the elderly population from 2010 to 2015 is used to calculate the population over 60 years old in each census-plot in 2015 . The data of diabetes 
patients were collected from the health records of diabetic patients in Yangpu District, Shanghai, 2015. The data attributes included individual's age, gender, home address, etc.

Since the built environment has a long-term and continuous effect on physical health, taking the registered population as the research object can reduce the impact of environmental changes on their health to some extent. According to the scale of resident population and registered residence population in each district of Yangpu District, the percentage of non-native populations in the Xinjiangwan Subdistrict was as high as $41.39 \%$, and there were few research samples located in this area. Therefore, the New Jiangwan Sub-district was removed from the study. The main research scope were 11 Sub-district in Yangpu, Shanghai. Population size and morbidity data of Yangpu District, Shanhai were shown in table 1.

The overall prevalence rate in Yangpu District of Shanghai (except Xinjiangwan Sub-district) was 10\%. Simple statistical description of the disease data was made and visualized in Arcgis 10.6, among which, Pingliang Sub-district (prevalence $=14.43 \%$ ) in the south of Yangpu District, Daqiao Street (prevalence $=13.45 \%$ ), Wujiaochang Sub-district in the middle of Yangpu District (prevalence $=12.14 \%$ ) and other areas had a high incidence of patients. The prevalence rates of Wujiaochang town (prevalence $=7.78 \%$ ) and Yinhang Sub-district (prevalence $=6.87 \%$ ) in the northeast of Yangpu District were low. It is preliminarily speculated that there was spatial difference in the prevalence of type 2 diabetes among people over the age of 60 in Yangpu District, Shanghai. It is preliminarily speculated that the prevalence of T2DM in the elderly over 60 years old in Yangpu District of Shanghai is spatially differentiated, and there may be a correlation between the prevalence and the built environment of different geographical locations, and further statistical tests have been carried out.

Table 1 Population size and morbidity data of Yangpu District, Shanhai, China

\begin{tabular}{|c|c|c|c|c|c|}
\hline name & $\begin{array}{l}\text { Registered } \\
\text { population }\end{array}$ & $\begin{array}{l}\text { Percentage } \\
\text { of non- } \\
\text { native } \\
\text { populations }\end{array}$ & $\begin{array}{l}\text { Elderly } \\
\text { populati } \\
\text { on } \\
\text { (age }>60)\end{array}$ & $\begin{array}{l}\text { Elderly population } \\
\text { with type } 2 \text { diabetes } \\
\text { mellitus } \\
\text { (age }>60)\end{array}$ & $\begin{array}{l}\text { Prevalence of } \\
\text { type } 2 \text { diabetes } \\
\text { mellitus } \\
\text { (age }>60)\end{array}$ \\
\hline $\begin{array}{l}\text { Pingliang Sub- } \\
\text { district }\end{array}$ & 65662 & $23.53 \%$ & 22216 & 3206 & $14.43 \%$ \\
\hline $\begin{array}{l}\text { Jiangpu } \\
\text { Sub-district }\end{array}$ & 76716 & $19.57 \%$ & 24298 & 2413 & $9.93 \%$ \\
\hline $\begin{array}{l}\text { Daqiao } \\
\text { Sub-district }\end{array}$ & 95897 & $23.25 \%$ & 31493 & 4235 & $13.45 \%$ \\
\hline $\begin{array}{l}\text { Kongjiang } \\
\text { Sub-district }\end{array}$ & 89792 & $14.98 \%$ & 29164 & 1896 & $6.50 \%$ \\
\hline $\begin{array}{l}\text { Siping } \\
\text { Sub-district }\end{array}$ & 77961 & $15.72 \%$ & 23298 & 3251 & $13.95 \%$ \\
\hline $\begin{array}{l}\text { Yanji new } \\
\text { village }\end{array}$ & 78415 & $13.19 \%$ & 28340 & 2742 & $9.68 \%$ \\
\hline Sub-district & & & & & \\
\hline $\begin{array}{l}\text { Changbai new } \\
\text { village }\end{array}$ & 59780 & $14.84 \%$ & 18309 & 2287 & $12.41 \%$ \\
\hline
\end{tabular}




\begin{tabular}{|c|c|c|c|c|c|}
\hline Sub-district & & & & & \\
\hline $\begin{array}{l}\text { Dinghai } \\
\text { Sub-district }\end{array}$ & 71163 & $29.18 \%$ & 21635 & 2431 & $11.24 \%$ \\
\hline $\begin{array}{l}\text { Wujiaochang } \\
\text { Sub-district }\end{array}$ & 113578 & $23.82 \%$ & 29987 & 3641 & $12.14 \%$ \\
\hline $\begin{array}{l}\text { Wujiaochang } \\
\text { town }\end{array}$ & 131625 & $26.46 \%$ & 36127 & 2811 & $7.78 \%$ \\
\hline $\begin{array}{l}\text { Yinhang } \\
\text { Sub-district }\end{array}$ & 161358 & $16.20 \%$ & 53819 & 3696 & $6.87 \%$ \\
\hline $\begin{array}{l}\text { Xinjiangwan } \\
\text { Sub-district }\end{array}$ & 15972 & $41.39 \%$ & - & - & - \\
\hline
\end{tabular}

Data source: Yangpu Yearbook (2015); China's Sixth Population Census Report; Health Department of Yangpu District, Shanghai.

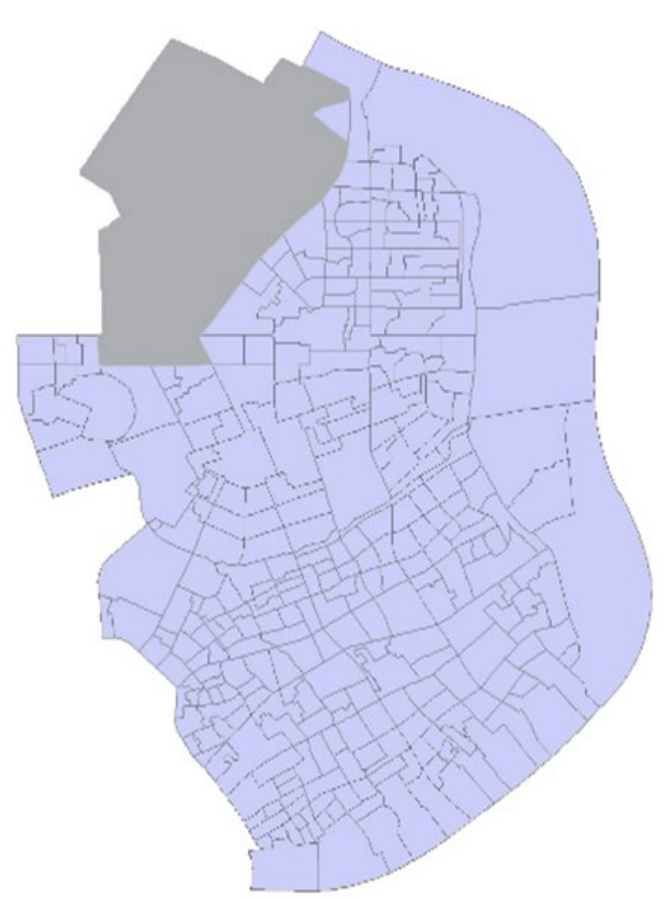

Figure 1 research area and research unit

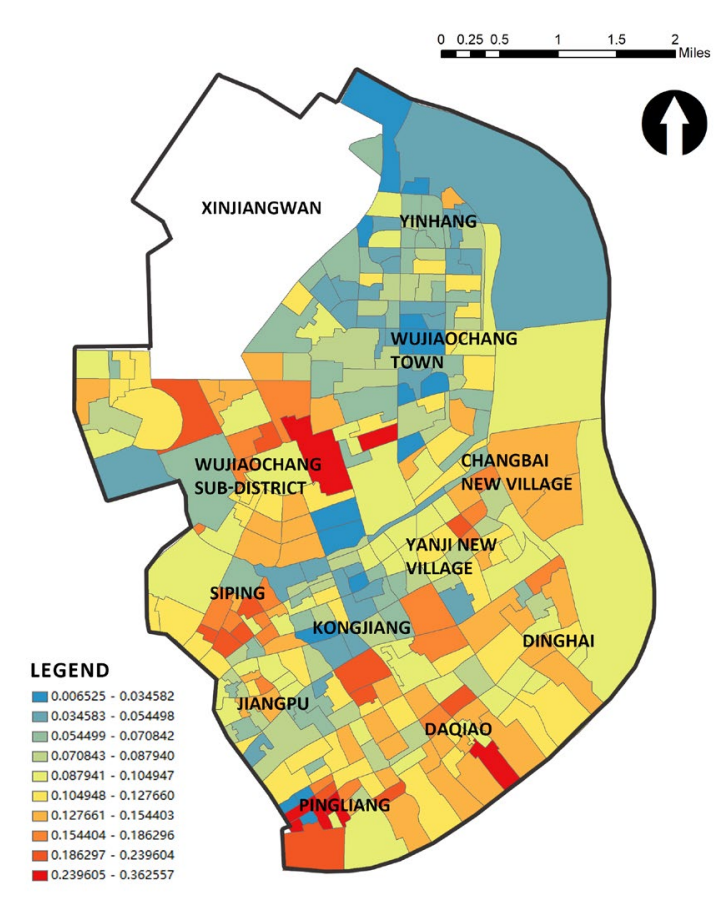

Figure 2 Prevalence of T2DM (age $>60$ ), Yangpu, Shanghai 


\subsection{Green space data}

In this study, the green space exposure level in Yangpu District was characterized by 2 indicators: green space availability and green space accessibility. The basic green space data comes from the satellite remote sensing data of Shanghai Institute of Surveying and mapping in 2015. According to the processing of remote sensing data, the green space coverage of each census district in Yangpu District was calculated. At the same time, according to the boundary of the residential area in Yangpu District provided by the Institute of Surveying and mapping, calculate the internal green space coverage of the residential community in the census district. The comprehensive index of green space accessibility was calculated by weighting the average shortest walking time of the residential area to the park within 15 minutes of walking around and the number of parks within 15 minutes of walking around. Previous studies often calculated OD distance through GIS network analysis to obtain the walking distance and time data from the residential community to the surrounding parks, which is different from the actual traffic situation. Through the API interface of AMAP, this study called the walking path planning function to obtain the real traffic data, and calculated the shortest walking time from the entrance and exit of the residential area to the park within a certain walking range, as well as the number of parks that can be reached within a certain walking time range, so as to truly reflect the accessibility of green space of the crowd.

\subsection{Analytical method}

\subsubsection{Ordinary Least Square}

Ordinary least squares regression analysis was used to study the relationship between the prevalence of type 2 diabetes and green spatial exposure variables in the elderly. Ordinary Least square method is a commonly used statistical method to explain the driving correlation between multiple independent variables and a single dependent variable. The calculation formula is as follows:

$$
y_{i}=\beta+\sum_{k=1}^{n} \beta_{k} x_{i k}+\varepsilon_{i}
$$

In the formula: $y_{i \mathrm{i}}$ the spatial ${ }^{i}$ position dependent variable (the prevalence of type 2 diabetes in the elderly). $\beta$ is the intercept of double multiplication space, $\beta_{k i}$ is the regression coefficient of the ${ }^{k}$ independent variable (green space exposure variable), and ${ }^{x_{i k} \text { is }}$ the value of the ${ }^{k}$ independent variable at space ${ }^{i}, \varepsilon_{i}$ is the algorithm residual.

However, at the same time, Ordinary Least Squares (OLS) model is a linear non spatial regression model. Its conclusion is to explore the regression of independent variables to dependent variables in the overall region, that is, it can not effectively reflect the regional influence of driving factors on dependent variables in different regions. Therefore, after using OLS method to preliminarily analyze the correlation, the study further studied it at the spatial level by using the geographically weighted regression (GWR) model.

\subsubsection{Geographical Weighted Regressive}

The Geographical Weighted Regressive method is an extension of the standard regression model and estimates that a large number of local parameters reflect the spatial changes in the relationship between epidemiological results and explanatory variables. Therefore, geographically weighted regression based on spatial heterogeneity, the model can better reflect the relationship of local geographic spatial 
dimensions, and clearly explain the mechanism of action of each influencing factor in different spatial locations with diagrams.

Through preliminary spatial autocorrelation analysis, the Moran's I index was used to detect the spatial autocorrelation of the prevalence of type 2 diabetes in the elderly over 60 years old in Yangpu District, Shanghai to test the spatial differentiation. The results showed (Moran's $I=0.29, Z=15.3, P=0.000$ ) The prevalence had a significant spatial clustered situation. Furthermore, the cold and hot spot analysis (Getis-Ord GI*, Figure 3) showed that there were hot spots in the areas of Pingliang Road Street, Siping Road Street, and the center of Wujiaochang Street in Yangpu District, that is, there were clusters of highprevalence census districts. Cold Spots appear in areas such as Kongjiang Road Street, Wujiaochang Town Center, Yinxing Street, etc., that is, there were clusters of low-to-low prevalence census districts. The results showed that the prevalence of type 2 diabetes in the elderly over 60 years old in Yangpu District of Shanghai was spatially heterogeneous.

Because the prevalence of type 2 diabetes in Yangpu District showed obvious spatial distribution differences, it is difficult to make the relationship between the green space explanatory variables and the prevalence of type 2 diabetes more realistically reflected only through the global regression model. In addition, due to the existence of spatial heterogeneity, the relationship between the independent variable and the dependent variable in different spatial sub-regions may be different. Previous studies had applied geographically weighted regression models to the study of diabetes and other diseases, the research results reflected that the correlation between explanatory variables and diabetes was very different in space. Therefore, in the study of the green space and the prevalence of type 2 diabetes in the elderly in this article, the OLS model is based The geographically weighted regression model is introduced above, and the model formula is as follows:

$$
\begin{gathered}
y_{i}=\beta_{0}\left(U_{i}, V_{i}\right)+\sum_{k=1}^{n} \beta_{k}\left(U_{i}, V_{i}\right) x_{k}\left(U_{i}, V_{i}\right)+\varepsilon_{i} \\
\beta_{k}\left(U_{i}, V_{i}\right)=\left(X^{\mathrm{T}} W\left(U_{i}, V_{i}\right) X\right)^{-1} X^{\mathrm{T}} W\left(U_{i}, V_{i}\right) y \\
W_{i j}=\exp \left(-d_{i j}^{2} / h^{2}\right)
\end{gathered}
$$

$\beta_{0}\left(\mathbb{V}_{i}, V_{i}\right): \quad\left(W_{i 2} V_{i}\right)$ Geographically weighted regression intercept of spatial location;

$\beta_{k}\left(U_{i k} V_{0}\right):$ The weighted regression coefficient of the ${ }^{k}$ independent variable in the ${ }^{\left(W_{i j} V_{i}\right)}$ spatial position;

$x_{k}\left(D_{i}, V_{i}\right):$ The value of the ${ }^{k}$ independent variable at the $\left(w_{b} V_{i}\right)$ spatial position;

$\varepsilon_{\llbracket:}$ Algorithm residual; $\mathbb{Z}^{\mathbb{P}}:$ Transposition of independent variables;

$W\left(U_{0}, V_{2}\right)$ : Distance weight matrix $k$ : Bandwidth of AIC criteria; $d_{4 h}$ : The distance between the position in space $\mathrm{i}$ and the position in space $\mathrm{j}$. 


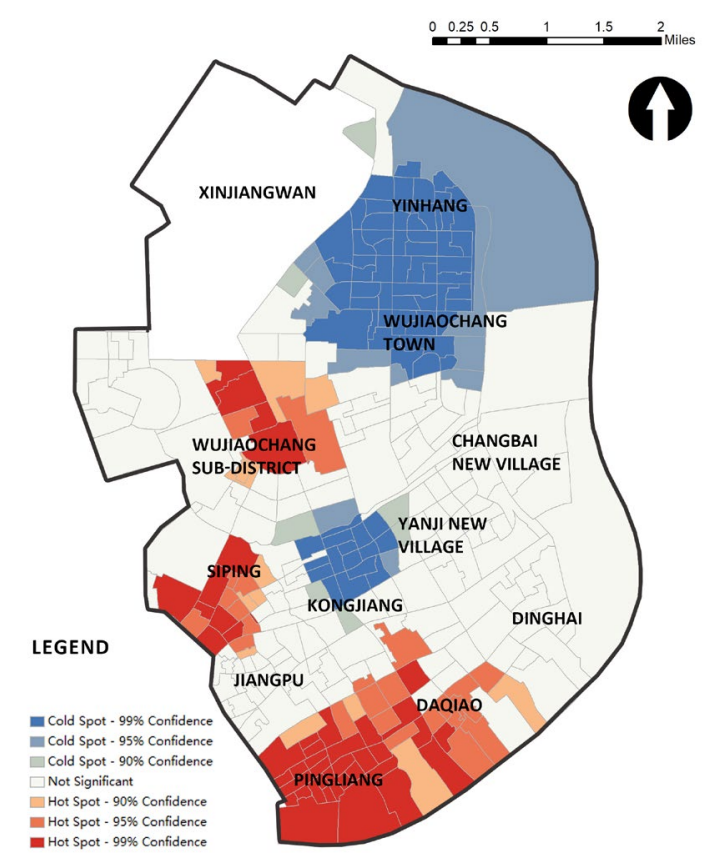

Figure 3 Result of Getis-Ord GI*

\subsubsection{Bivariate local Moran's I statistic}

Spatial autocorrelation based on bivariate has high applicability and effectiveness in describing the spatial correlation and dependence characteristics of two geographic elements. Bivariate local Moran's I statistic can be used to explore the spatial correlation characteristics of the two, and the result represents the overall spatial distribution correlation between the independent variable of area $i$ and the dependent variable of area $\mathrm{j}$. The result of bivariate local spatial autocorrelation is the local correlation between the independent variable of area $i$ and the dependent variable of area $j$, which can be divided into $\mathrm{HH}$ (HighHigh), LL (Low-Low), HL (High-Low) and LH (Low-High) 4 types of aggregation. This study uses bivariate spatial autocorrelation to analyze the spatial distribution coordination (coupling) between green space exposure variables, prevalence, and green space exposure variables. It aims to combine with the GWR results and assist in the study of the space distribution relationship between variables.

\section{RESULT}

OLS results showed (Table 3) that the three green space exposure variables in Yangpu District had a significant negative correlation with the prevalence of type 2 diabetes in the elderly over 60 years old. Overall, it reflected that the increase in green space exposure had a positive effect on the reduction of the prevalence of type 2 diabetes to a certain extent. The GWR analysis results showed that the overall model goodness of fit increased from 0.39 to 0.47 , the AICC value decreased from 1056.7 to 943.6, and the fitting result had improved. From the estimation results of the GWR model, it is compared with the linear regression of OLS which introduces the spatial distance weight, and the evaluation result had the reliability of the spatial scale. The model could obtain the regression coefficients corresponding to the respective variables in 310 census districts. In the area where the model fits well $\left(R^{\wedge} 2>0.2\right)$, the overall regression coefficients of each variable are shown in the Table 4. 
Table 2 Statistical analysis on variables

\begin{tabular}{lccccc}
\hline Variable Name & $\mathbf{n}$ & Mean & SD & Miminum & Maximum \\
\hline $\begin{array}{l}\text { Ratio of neighborhood green } \\
\text { space }\end{array}$ & 310 & 0.212 & 0.107 & 0 & 0.638 \\
$\begin{array}{l}\text { Ratio of residential area } \\
\text { green space }\end{array}$ & 310 & 0.269 & 0.128 & 0 & 0.907 \\
$\begin{array}{l}\text { Comprehensive green space } \\
\text { accessibility index }\end{array}$ & 310 & 0.556 & 0.231 & 0 & 1 \\
$\begin{array}{l}\text { Prevalence of Type 2 } \\
\text { diabetes mellitus }\end{array}$ & 310 & 0.105 & 0.054 & 0.006 & 0.363 \\
$\begin{array}{l}\text { (age>60) } \\
\text { (ab) }\end{array}$ & & & & \\
\hline
\end{tabular}

Table 3 Results of OLS model regression

\begin{tabular}{llll}
\hline Variable Name & Coefficient & StdError & Probability[b] \\
\hline${ }^{*} \beta$ & 0.156 & 0.009 & $0.001^{*}$ \\
$\begin{array}{l}\text { Ratio of neighborhood } \\
\text { green space }\end{array}$ & -0.145 & 0.037 & $0.000^{* * *}$ \\
$\begin{array}{l}\text { Ratio of residential area } \\
\text { green space }\end{array}$ & -0.102 & 0.031 & $0.012^{*}$ \\
$\begin{array}{l}\text { Comprehensive green space } \\
\text { accessibility index }\end{array}$ & -0.094 & 0.122 & $0.003^{* *}$ \\
\hline$* \beta \cdot$ Spatial intercept of OlS model $* * * * * *$ mean $\mathrm{P}<0.05, \mathrm{P}<0.01, \mathrm{P}<0.001$
\end{tabular}

$* \beta$ : Spatial intercept of OLS model. ${ }^{*}, * *, * * *$ mean $\mathrm{P}<0.05, \mathrm{P}<0.01, \mathrm{P}<0.001$

Table 4 Coefficient of variables on GWR model

\begin{tabular}{lllll}
\hline & Coefficient & & \\
\hline Variable Name & Mean & StdError & Miminum & Maximum \\
$\begin{array}{l}\text { Ratio of neighborhood green } \\
\text { space (Co1) }\end{array}$ & -0.145 & 0.116 & -0.417 & -0.191 \\
$\begin{array}{l}\text { Ratio of residential area } \\
\text { green space (Co2) }\end{array}$ & -0.083 & 0.076 & -0.242 & -0.041 \\
$\begin{array}{l}\text { Comprehensive green space } \\
\text { accessibility index (Co3) }\end{array}$ & -0.049 & 0.034 & -0.114 & -0.033 \\
\hline
\end{tabular}

In general, the regression coefficient $\left(-0.421<\beta_{c}<-0.003\right)$ of the overall green space exposure variable in the area where the model fits well $(R>0.2)$ was negative, indicating that the overall green space exposure variable was related to the elderly with type 2 diabetes. There is a significant negative correlation in the morbidity, which is consistent with the results of OLS. Comparing the absolute value of the regression coefficient $\beta_{c}$ in different regions, we could find that the overall adjustment strength of the green space exposure variable on the prevalence rate showed a trend of high in the southwest and 
low in the northeast. This meant that increasing the green space exposure level of Wujiaochang Street, Siping Road Street, Pingliang Road Street and other areas will have more significant benefits in reducing the prevalence of type 2 diabetes in the elderly.

From the regression coefficients of the three variables in different regions, in the region the model fit well,the ratio of neighborhood committee green space $(-0.191<$ Co $<-0.417)$, the ratio of green space in residential area $(-0.041<\mathrm{Co}<-0.242)$, the comprehensive green space accessibility index $(-0.033<\mathrm{Co}<-$ 0.114 ) were had a certain negative impact on T2DM. Using GIS to visualize the regression coefficients of the significant variables in each census district, you can more intuitively and clearly see the effect of each factor on the dependent variable and the spatial difference of the strength of this effect, so as to have a clearer understanding of the green space exposure variables in Yangpu District Impact on the prevalence of type 2 diabetes in the elderly and spatial differences.

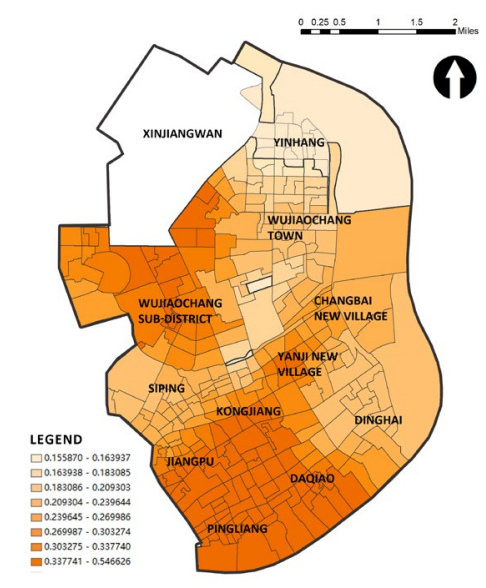

Figure4 $\mathbf{R}^{\wedge} \mathbf{2}$ Visualization results

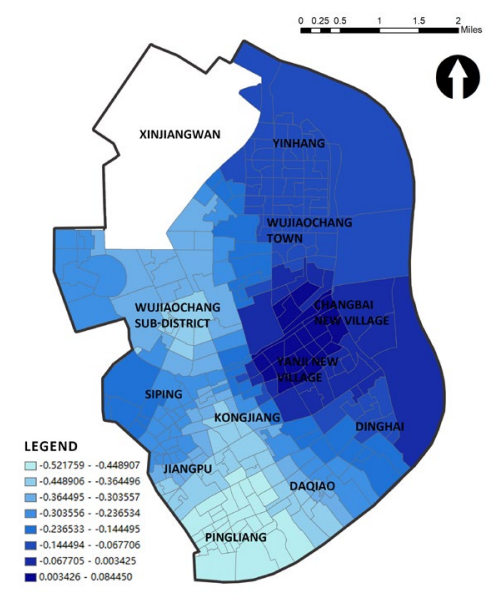

Figure5 Co Visualization results

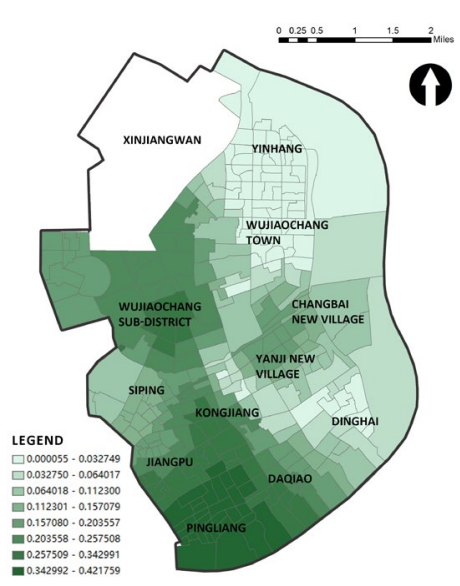

Figure6 Absolute value of Co Visualization results

\subsection{Ratio of neighborhood green space and Prevalence of T2DM}

The coverage rate of green space in the census district can reflect the supply of urban green space at the level of the census district, and is the ratio of the green space coverage in the census cell to the area of the census cell. The GWR analysis results were shown in the figure. In areas where the model fits well, the regression coefficients were all negative, indicating that there was a negative correlation between the coverage of green space in the census district in these areas and the prevalence of type 2 diabetes in the elderly. That is, the increase in the coverage of green space in the census district in the region could reduce the prevalence of type 2 diabetes in the elderly to a certain extent. Comparing the absolute value and spatial distribution of the regression coefficients, it could be seen more intuitively that the impact of the coverage of green space in the census district on the prevalence of type 2 diabetes in the elderly in Yangpu District showed a gradual weakening trend from the southwest to the northeast of the study area, with the largest absolute value appeared in Kongjiang Road Sub-district $(\mathrm{Co}=-0.417)$, indicating that under the control of other variables, for every district increase in the coverage of green space in the census district, the prevalence of type 2 diabetes in the elderly in Kongjiang Road Sub-district would decrease by 0.417 units. Therefore, compared with other streets in Yangpu District, increasing the coverage of green space in the census district had a more positive and significant effect on improving the health of the elderly in Kongjiang Road Street, Pingliang Road Street, Jiangpu Road Street and Daqiao Road Street. 
From the results of the bivariate spatial autocorrelation analysis, there are significant high (prevalence)low (green areas in the census area) clusters in the Pingliang Road street and the riverside area in the south of Yangpu District. To a certain extent, it reflected the urgent need to supplement the green space in this area. In the past, large areas of Shanghai's old industrial zone were scattered in the riverside area. The green space resources for recreation and sports and fitness were scarce, which potentially affected healthy quality of life of the residents. Comparing the Bi-LISA values, it found that the aggregation phenomenon of low (prevalence)-low (green space rate in the census area) was more intense (prevalence)-high (green space rate in the census area), and the aggregation phenomenon was less significant. Combined with the GWR results, the analysis showed that the adverse effects of insufficient supply of green space on the prevalence of type 2 diabetes in the elderly were more prominent than the positive effects. Therefore, it is very important to increase the supply of green space in areas with high prevalence.

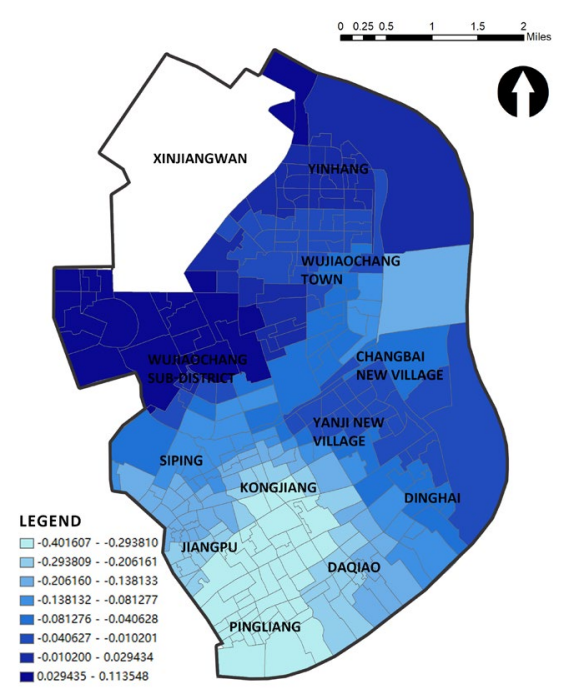

Figure7 Co1 Visualization results

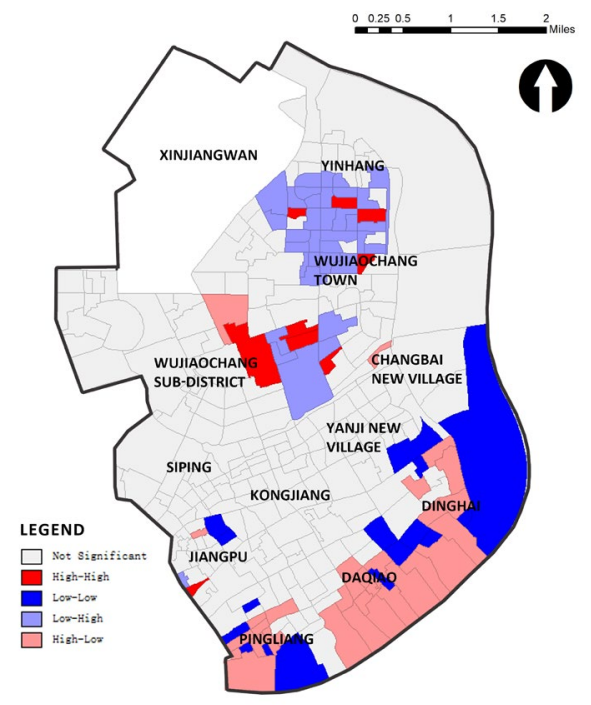

Figure9 Results of Bi-Moran's I

(Ratio of neighborhood green space and T2DM)

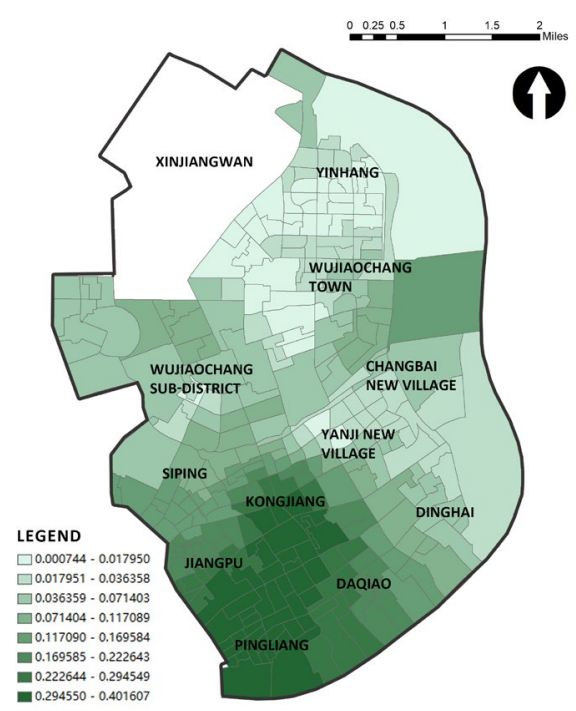

Figure8 Absolute value of Co1 Visualization results

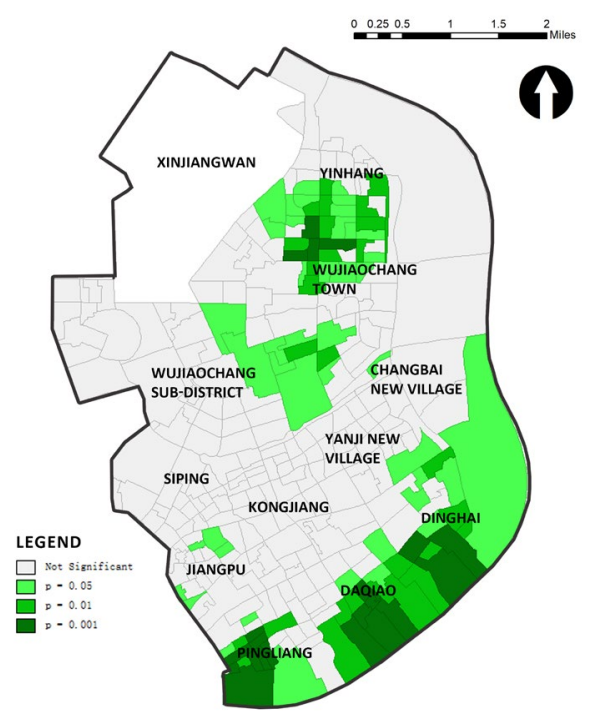

Figure10 Results of Bi-LISA

(Ratio of neighborhood green space and T2DM) 


\subsection{Ratio of residential area green space and Prevalence of T2DM}

Compared with the community green space, the green space inside the residential courtyard is closely related to the daily life of the elderly in the courtyard, and the frequency of use is higher than that of the green space outside the courtyard. However, due to the existence of the courtyard wall, its supply is somewhat private.The service target is the crowd in the courtyard. The green space coverage rate of residential courtyards can directly reflect the supply of green space at the residential courtyard level in the census district, and is the average value of the green space coverage rates of the residential courtyards in the census district.

Comparing the absolute value and spatial distribution of the regression coefficients, it can be seen intuitively that the area with the highest impact on the prevalence of type 2 diabetes in the elderly in Yangpu District by the coverage of the census community was located in the middle of Yangpu District, represented by Wujiaochang Street. The largest absolute value appears in Wujiaochang Street $(\mathrm{Co}=0.242)$. Under the control of other variables, every increase in the green coverage rate of residential courtyards would reduce the prevalence of type 2 diabetes in the elderly in Wujiaochang Street by 0.242 units. Increasing the green coverage rate of residential courtyards could reduce the prevalence of type 2 diabetes in the elderly in Wujiaochang Street to a certain extent.

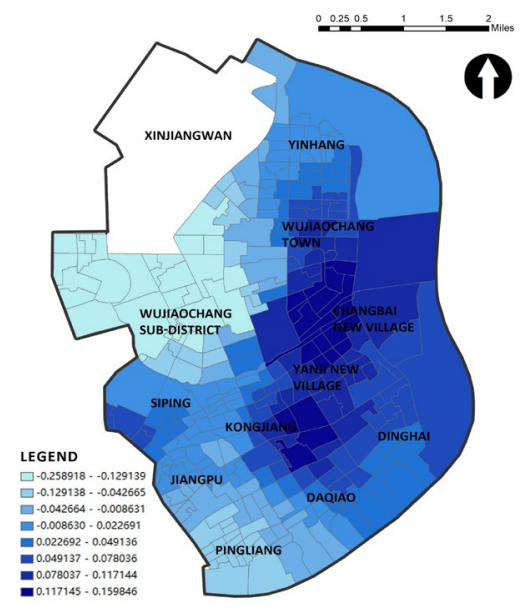

Figure11 Co2 Visualization results

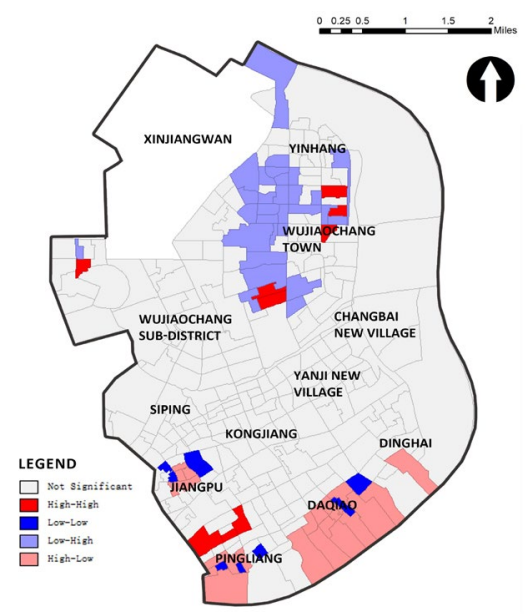

Figure13 Results of Bi-Moran's I

(Ratio of residential area green space and T2DM)

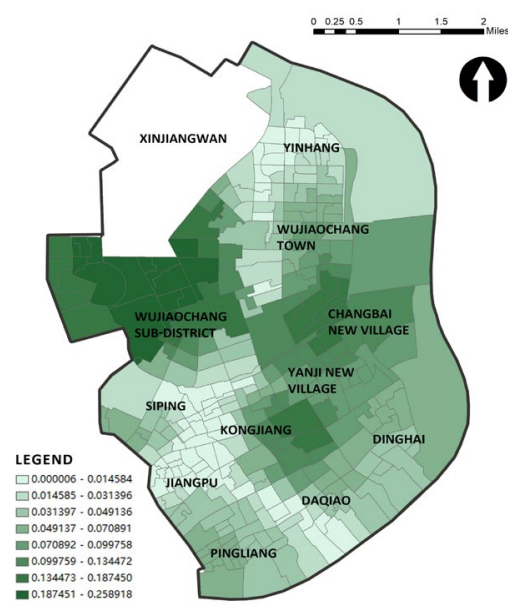

Figure12 Absolute value of $\mathrm{Co} 2$ Visualization results

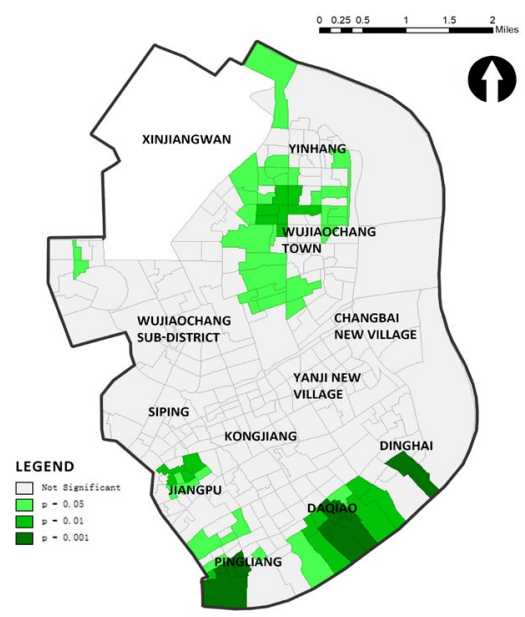

Figure14 Results of Bi-LISA

(Ratio of residential area green space and T2DM) 
From the results of bivariate spatial autocorrelation analysis, it is similar to the spatial synergy of green space coverage and prevalence in the census district. In the southern Pingliang Road and Binjiang area of Yangpu District, there was a significant high (prevalence)-low (Residential courtyard green space rate) In the gathering area, there was a low (prevalence rate)-high (residential courtyard green space rate) aggregation phenomenon in Yinhang Street.

\subsection{Comprehensive green space accessibility index and Prevalence of T2DM}

The accessibility index of green space affects the actual use of green space. The high accessibility of parks and green spaces means that the elderly can easily reach and use them and promote their physical activities. On the contrary, the low-accessibility of parks and green spaces restricts the elderly from physical activities to a certain extent. Comparing the absolute value and spatial distribution of the regression coefficients, it can be seen intuitively that it is similar to the rate of green space in residential courtyards. The area where the comprehensive green space walkability index had the highest impact on the prevalence of type 2 diabetes in the elderly located in the central and southern riverside areas of Yangpu district. The maximum absolute value of the regression coefficient appeared in Wujiaochang Street $(\mathrm{Co}=0.114)$. Under the control of other variables, for every increase in the green coverage rate of residential courtyards, the prevalence of type 2 diabetes in the elderly in Wujiaochang Street will decrease by 0.114 In units, improving the walkability of green space can reduce the prevalence of type 2 diabetes in the elderly in Wujiaochang Street to a certain extent.

From the results of the bivariate spatial autocorrelation analysis, high (prevalence)-high (comprehensive green space walkability) clustered areas appeared in the middle of Yanji New Village and the middle of Yinhang Street, while low (Prevalence)-high (comprehensive green space walkability) gathering area. Based on the analysis of the GWR results, the high-high concentration areas were mainly around several large parks. This showed that when the potential support for people to use the park increased with the shortening of the distance and the improvement of accessibility, there may have a marginal effect in the process. When the distance from the park is less than the critical value, the relationship between the comprehensive green space walkability and the prevalence is weakened.

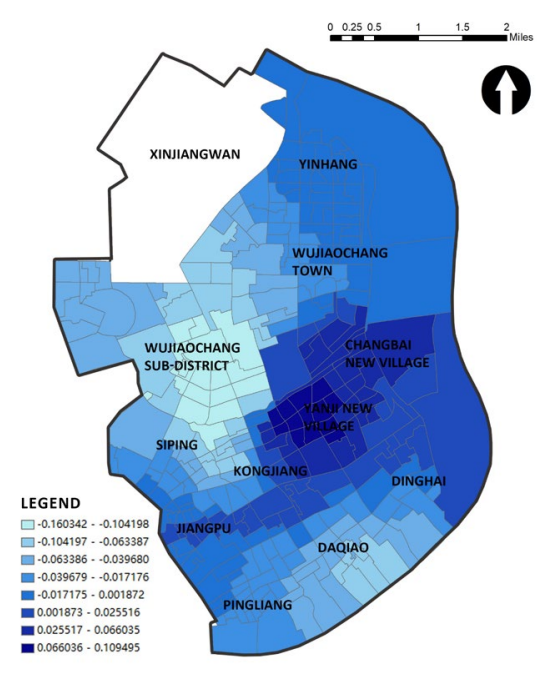

Figure7 Co3 Visualization results

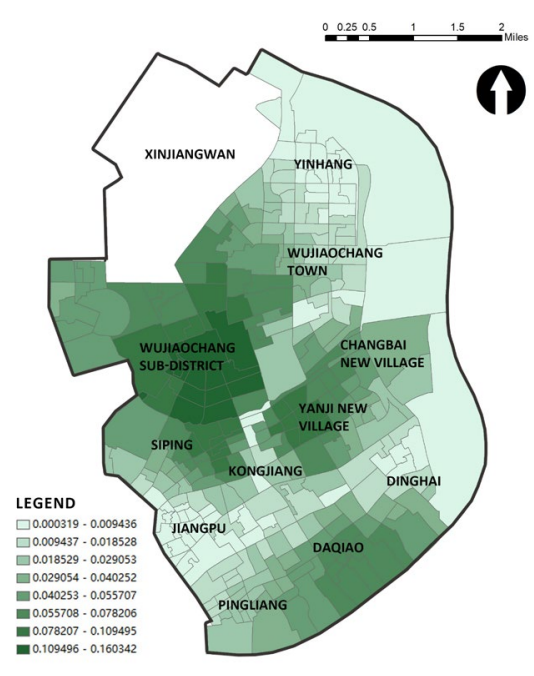

Figure8 Absolute value of $\mathrm{Co} 3$ Visualization results 


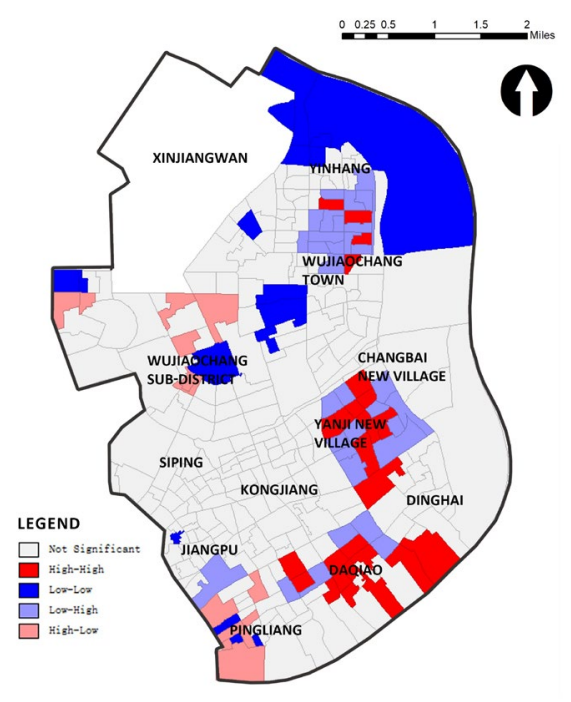

Figure9 Results of Bi-Moran's I

(Green space accessibility index and T2DM)

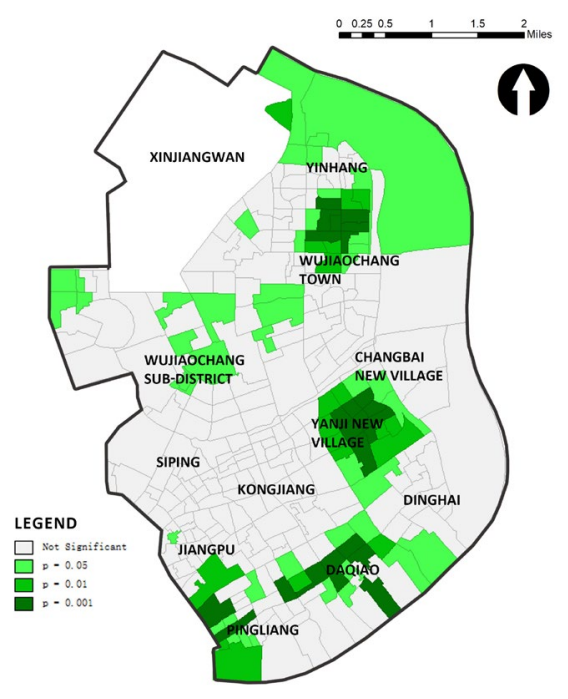

Figure10 Results of Bi-LISA

(Green space accessibility index and T2DM)

\subsection{Layout and structure of green space in Yangpu District}

The statistical results of the bivariate spatial autocorrelation between the green space coverage rate of the census district, the green space coverage rate of residential courtyards, and the green space accessibility index showed that ,similarly, "high ( Green space coverage)-low (green space accessibility)" aggregation phenomenon, which shows that although the green space coverage in these areas is high, the green space accessibility is low. This may cause obstacles to the actual use of green space by the elderly. Considering from the planning strategy, in the future, these areas should first improve the accessibility of green space, rather than the scale of green space. In fact, there are many factors that affect the accessibility of green spaces. From the perspective of bivariate spatial autocorrelation analysis, the area and quantity of green spaces are not the main factors that affect the accessibility of green spaces in these areas. There may be many other built environment factors, such as road network density, which mav affect the green space accessibilitv of these areas bv affecting the arrival time.

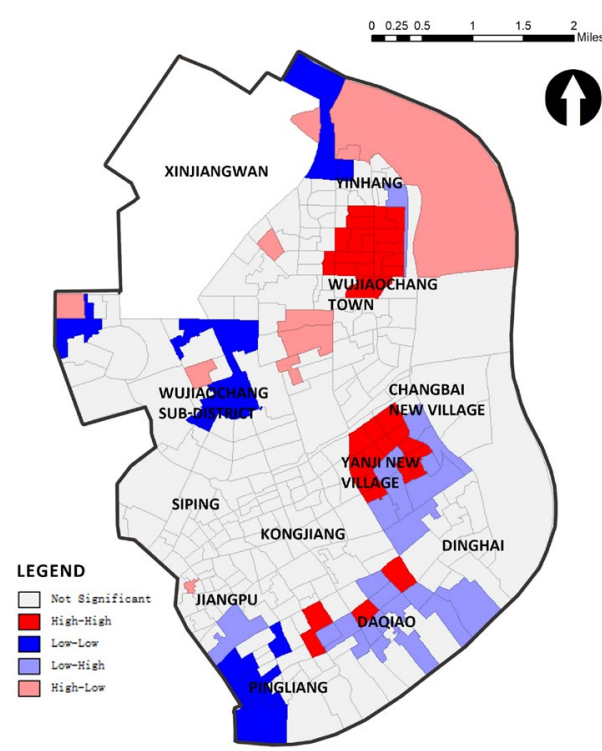

Figure9 Results of Bi-Moran's I

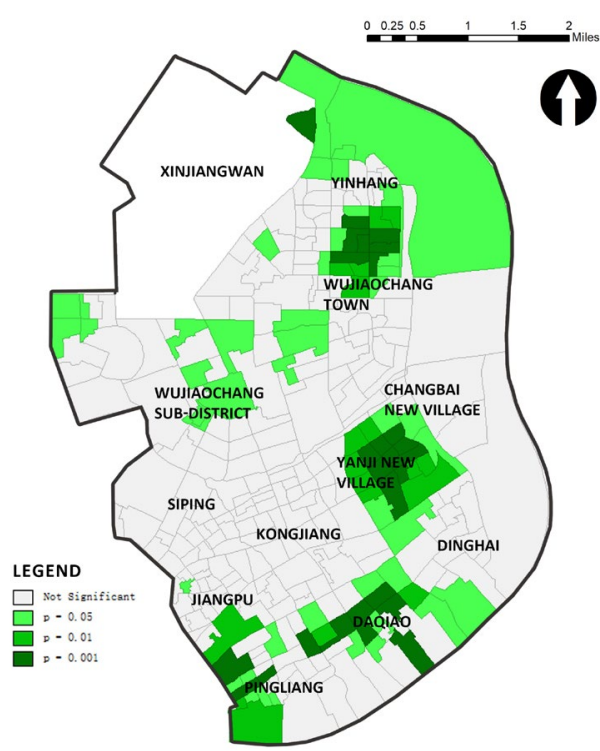

Figure10 Results of Bi-LISA

(Ratio of neighborhood green space and green space accessibility index) 


\section{DISCUSSION}

Based on OLS and GWR analysis results, it was revealed that improving the green space coverage rate of census communities, the green space coverage rate of residential courtyards and the walking accessibility index of green space had positive effects on reducing the prevalence of type 2 diabetes in the elderly. It is worth noting that compared with the regression coefficients of other variables, the coverage rate of green space in census communities in the study area has the most significant impact on the prevalence of type 2 diabetes among the elderly. This indicates that adjusting the green space exposure variables to improve the built environment health and increasing the supply area and quantity of green space to improve the availability of green space are still the fundamental measures to improve the exposure level of green space. The study also revealed that the coverage of green space in residential courtyards and the walking accessibility of green space in actual use had positive effects on the reduction of the prevalence of type 2 diabetes among the elderly. The health outcomes of the elderly in different regions are the comprehensive effects of multiple factors. When improving the exposure level of green space in each region, measures should be taken according to local conditions. It is easier to grasp the entry point from different angles according to the significance of factors.

In particular, for a metropolis with a high-density built environment like Shanghai, urban land is very tight, and increasing large-scale green space is a huge challenge, which urges urban planning to pay more attention to the improvement of the supply of green space in communities and residential courtyards related to the daily life of the elderly. In the planning practice of Shanghai in recent years, the concept of 15-minute community living circle gradually emerged, and corresponding requirements were put forward to supplement and improve the coverage rate of green space. For example, the service radius of small green space should not exceed 300 meters, and the service radius should not exceed 150 meters in areas with high population density. Improve the systematic and networked layout of community green space, build green trails to meet the needs of People's Daily leisure walking, running and fitness, commercial leisure activities, and create an active living community. In addition, special emphasis is placed on the design of green space for different groups of people, encouraging the improvement of the openness of the existing green space to meet the needs of fitness and leisure activities of the elderly, especially considering the setting requirements of barrier-free facilities. In recent years, community micro-update has attracted much attention in Shanghai urban renewal. Drawing on the international experience of pocket parks and flash parks, it is an efficient way to improve the efficiency of redesigning and constructing a batch of delicate and convenient small green Spaces by excavating scattered lands such as "corners" and "sandwiches" in established areas. Its advantages lie in low cost, quick effect and strong sense of acquisition by residents.

In fact, most international studies believe that the health promotion mechanism of green space can be divided into mediating mechanism and regulating mechanism. When studying the impact of green space on health, this influencing factor is the intermediary mechanism. The path and reason for the effect of the intermediary are the intermediary mechanism, and the intermediary reflects how green space affects the problem. For example, green space promotes the health level by promoting the generation of healthy behaviors and activities. In this study, although the correlation between green space exposure variables and the prevalence of type 2 diabetes in the elderly was statistically revealed, the mediating mechanism of the influence of green space exposure variables was lacking

The deficiency will be further studied in the future. 


\section{References}

AGREN G, BERENSSON K. Healthy ageing-a challenge for Europe[R]. Stockholm: Swedish National Institute of Public Health, 2006.

HIGGS P, HYDE M, WIGGINS R, et al. Researching quality of life in early old age: the importance of the sociological dimension[J]. Social Policy \& Administration, 2003, 37(3): 239-252.

World Health Organization. WHO global network of age-friendly cities and communities[R]. Geneva: WHO, 2013.

World Health Organization. Global age-friendly cities: A guide[M]. Geneva: World Health Organization, 2007.

World Health Organization. Measuring the age-friendliness of cities: a guide to using core indicators[M]. Kobe: WHO Centre for Health Development, 2015.

PLOUFFE L, KALACHE A. Towards global age-friendly cities: determining urban features that promote active aging[J]. Journal of Urban Health Bulletin of the New York Academy of Medicine, 2010, 87(5): 733-739.

KENT J L, THOMPSON S. The three domains of urban planning for health and well-being[J]. Journal of Planning Literature, 2014, 29(3): 239-256.

STEELS S. Key characteristics of age-friendly cities and communities: A review[J]. Cities, 2015, 47: 45-52.

Lee CMY, Colagiuri R, Magliano DJ, et al. The cost of diabetes in adults in Australia. Diabetes Res Clin Pract 2013;99:385-390

International Diabetes Federation: Diabetes Atlas.2015. http://indiaenvironmentportal.org.in/files/file/IDF Atlas\%202015_UK.pdf

ChoN H, Shaw J E, Karuranga S, et al. IDF Diabetes Atlas: Global estimates of diabetes prevalence for 2017 and projections for 2045[J]. Diabetes Research and Clinical Practice, 2018,138: 271-281.

Colagiuri S, Vita P, Cardona-Morrell M, et al. The Sydney Diabetes Prevention Program: a communitybased translational study. BMC Public Health 2010;10:328

Nilsson K, Sangster M, Konijnendijk CC. Introduction. In Forests, Trees and Human Health. Nilsson K, Sangster M, Gallis C, et al, Eds. Netherlands, Springer, 2011, p. 1-19

Maas J, Verheij RA, de Vries S, Spreeuwenberg P, Schellevis FG, Groenewegen PP. Morbidity is related to a green living environment. J Epidemiol Community Health 2009;63:967-973

Astell-Burt T, Feng X, Kolt G S. Is Neighborhood Green Space Associated With a Lower Risk Of Type 2 Diabetes? Evidence From 267,072 Australians[J]. Diabetes Care, 2014, 37(1): 197-201.

Den Braver N R, Lakerveld J, Rutters F, et al. Built environmental characteristics and diabetes: a systematic review and meta-analysis[J]. Bmc Medicine, 2018, 16.

Dendup T, Feng X, Clingan S, et al. Environmental Risk Factors for Developing Type 2 Diabetes Mellitus: A Systematic Review|J ]. International Jourmal of Environmental Research and Public Health, 2018, 15(1). 